\title{
Preparação, Caracterização e Degradação de Blendas PS/TPS Usando Glicerol e Óleo de Buriti como Plastificantes
}

\author{
Daniela Schlemmer, Maria J. A. Sales \\ Laboratório de Pesquisa em Polímeros, Instituto de Química, UnB \\ Inês S. Resck \\ Laboratório de Ressonância Magnética Nuclear, Instituto de Química, UnB
}

\begin{abstract}
Resumo: Poliestireno (PS) é um dos materiais descartáveis mais usados no nosso cotidiano, mas ele não se decompõe facilmente. A adição de amido de mandioca ao PS pode melhorar a sua degradabilidade, tendo em vista ser o amido um polímero biodegradável. O objetivo deste trabalho foi desenvolver blendas de PS e (amido termoplástico) TPS usando dois diferentes plastificantes: glicerol e óleo de buriti, sendo esse óleo um plastificante natural e original para o amido. As blendas PS/TPS foram preparadas em diversas composições por casting e em seguida caracterizadas por termogravimetria (TG), calorimetria exploratória diferencial (DSC), análise termomecânica (TMA) e ressonância magnética nuclear (RMN) ${ }^{13} \mathrm{C}$. As blendas PS/TPS com óleo de buriti apresentaram uma contínua redução em suas $\mathrm{T}_{\mathrm{g}}$ e $\mathrm{T}_{\mathrm{a}}$. Nas blendas com glicerol esses parâmetros permaneceram praticamente constantes. As blendas também foram submetidas a testes de degradação no solo e depois analisadas por TG e RMN. A análise das blendas PS/TPS com óleo de buriti mostrou que houve um aumento da perda de massa nas curvas TG. Nos espectros de RMN ${ }^{13} \mathrm{C}$, todos os picos referentes ao amido desapareceram, depois do teste de aterro, sugerindo que houve consumo do amido das blendas por microorganismos. De acordo com as análises realizadas, a adição do TPS produzido com óleo de buriti pode melhorar a degradabilidade do PS.
\end{abstract}

Palavras-chave: Amido termoplástico, óleo de buriti, plastificante, degradação.

\section{Preparation, Characterization and Degradation of PS/TPS Blends Using Glycerol and Buriti oil as Plastiscizers}

\begin{abstract}
Polystyrene (PS) is one of the most used disposable materials in our daily life, but it does not decompose easily. The addition of cassava starch to PS can improve its degradability since starch is a biodegradable polymer. The aim of this work was to develop blends of PS and thermoplastic starch (TPS) using two different plasticizers: buriti glycerol and buriti oil, a novel and natural plasticizer for starch. PS/TPS blends were prepared in various contents with the casting technique and analyzed by thermogravimetry (TG), differential scanning calorimetry (DSC), thermomechanical analysis (TMA) and ${ }^{13} \mathrm{C}$ nuclear magnetic resonance (NMR). PS/TPS blends with buriti oil presented a continuous reduction in $\mathrm{T}_{\mathrm{g}}$ and $\mathrm{T}_{\mathrm{a}}$. For blends with glycerol these parameters remained practically constant. PS/TPS blends were submitted to degradation by soil burial testing and then analyzed by TG and ${ }^{13} \mathrm{C}$ NMR. The analysis of PS/TPS blends with buriti oil indicated an increase in weight loss in the TG curves. All NMR peaks associated with starch disappeared after the soil burying test, probably due to the consumption of starch by microorganisms. The results showed that addition of TPS produced with buriti oil to PS can probably improve its degradability.
\end{abstract}

Keywords: Thermoplastic starch, buriti oil, plastiscizer, degradation.

\section{Introdução}

A crescente preocupação com o desenvolvimento sustentável tem despertado a atenção da indústria para os biopolímeros derivados de recursos agrícolas renováveis. $\mathrm{O}$ amido é bastante estudado nessa área por ser natural, barato e renovável.

O amido é um material de reserva encontrado em grãos, tubérculos e raízes, constituído pela mistura dos polissacarídeos amilose e amilopectina. A molécula de amido tem dois importantes grupos funcionais: o grupo -OH que é suscetível a reações de substituição e a ligação glicosídica $\mathrm{C}-\mathrm{O}-\mathrm{C}$, suscetível à quebra de cadeia. $\mathrm{O}$ grupo hidroxila da glicose tem caráter nucleofílico ${ }^{[1]}$.

A amilose e a amilopectina, constituintes do amido, são formadas por unidades do tipo $(1,4)$ - $\alpha$-D-glicose na forma piranosídica. A amilose é essencialmente linear e, apesar disso, apresenta uma estrutura que dificulta sua associação regular com outras cadeias, formando a parte

Autor para correspondência: Maria J. A. Sales, Universidade de Brasília, Caixa Postal 4478, CEP: 70904-970, Brasília, DF, Brasil. E-mail: mjsales@unb.br 
amorfa do grânulo. A amilopectina é altamente ramificada; seus segmentos lineares estão arranjados como estruturas helicoidais duplas, estabilizadas por ligações de hidrogênio entre grupamentos hidroxila ${ }^{[2,3]}$. Assim, a cristalinidade do amido é atribuída principalmente à amilopectina ${ }^{[4]}$.

Para se obter o amido termoplástico (TPS) é necessário destruir a estrutura semicristalina original dos grânulos. Para isso, o amido nativo deve ser aquecido a altas temperaturas (90-180 ${ }^{\circ} \mathrm{C}$ ) na presença de plastificantes e sob agitação, de forma que adquira características similares à maioria dos termoplásticos convencionais ${ }^{[1]}$. Porém, o TPS apresenta duas desvantagens principais quando comparado à maioria dos plásticos em uso: é geralmente solúvel em água e apresenta propriedades mecânicas pobres. Essas podem ser amenizadas adicionando o TPS a polímeros sintéticos ${ }^{[5-10]}$.

Plastificantes são aditivos muito empregados em materiais poliméricos para melhorar a processabilidade e aumentar a flexibilidade. São substâncias com massa molecular menor em relação ao polímero e formam com ele um material aparentemente homogêneo, mais macio, mais flexível e mais fácil de processar ${ }^{[11]}$.

Já existem vários trabalhos citando o uso de óleos vegetais como aditivos de materiais poliméricos. Fang et al. ${ }^{[12]}$ usaram um derivado de ácido graxo $(\mathrm{C} 18: 1, Z)$ como plastificante. Eles mostraram que a incorporação de cadeias laterais ao polímero provoca um impacto significativo na plasticidade do material. Durães et al. ${ }^{[13]}$ mostraram que quando o óleo de buriti é misturado a polímeros petroquímicos são obtidos materiais fotoprotetores e fotoluminescentes, mais flexíveis e com excelente estabilidade térmica. Pimentel et al. ${ }^{[14]} \mathrm{e}$ Schlemmer et al. ${ }^{[15]}$ mostraram que o óleo de buriti pode agir como plastificante de filmes de amido. O óleo de buriti é líquido a temperatura ambiente e apresenta coloração alaranjada. Seu componente majoritário $(\sim 76 \%)$ é o ácido oléico. É também rico em Vitamina A e apresenta grande quantidade de carotenóides, sobretudo $\beta$-caroteno ${ }^{[16]}$.

A mistura de polímeros é uma rota economicamente viável para melhorar as propriedades dos materiais poliméricos já existentes. Blendas são materiais originários de dois ou mais polímeros com características constitucionais ou configuracionais diferentes, e que possuem baixo grau de ligação química entre $\mathrm{si}^{[17]}$. A produção de blendas de amido com polímeros petroquímicos tem a intenção de encontrar uma solução para os problemas causados por estes plásticos, que levam séculos para se degradarem na natureza. A adição do amido é considerada como alternativa viável para acelerar o ataque de microorganismos e garantir pelo menos uma biodegradação parcial. Os microorganismos consomem o amido circundante, o plástico perde sua integridade estrutural. Esse processo faz com que haja deterioração das propriedades mecânicas, facilitando a quebra do material por outros mecanismos de degradaçãó ${ }^{[6,7]}$.

Zuchowska et al. ${ }^{[5]}$ investigaram as propriedades do amido gelatinizado adicionado ao PE e ao PP e concluíram que as propriedades mecânicas das blendas dependem fortemente da sua composição. Foi observado também um aumento na suscetibilidade à degradação da fase polimérica e não apenas da porção que continha amido. Kiatkamjornwong et al. ${ }^{[6]}$ estudaram filmes de amido de mandioca com PS e encontraram que as suas propriedades físicas são rapidamente deterioradas após exposição ao meio ambiente ou à luz UV. O efeito da quantidade de amido nas propriedades físicas do polietileno de baixa densidade (LDPE) foi pesquisado por Thakore et al. ${ }^{[7]}$. Suas pesquisas destacaram que a incorporação de amido conduz a um comportamento amorfo da matriz de LDPE. El-Rehim et al. ${ }^{[8]}$ avaliaram o comportamento de blendas de LDPE e amido expostas à radiação UV e posteriormente enterradas no solo. Os resultados obtidos indicaram que o efeito sinérgico resultante da combinação desses dois fatores provocou um aumento na taxa de biodegradação das blendas. Ramis et al. ${ }^{[9]}$ estudaram a biodegradabilidade de blendas de amido e PP. Seus estudos mostraram que as blendas sofrem algum tipo de transformação que pode ser comprovada pelo surgimento de um segundo estágio de degradação nas curvas termogravimétricas. Nakamura et al. ${ }^{[10]}$ incorporaram diferentes tipos de amido ao LDPE para verificar a possibilidade de obter um polímero parcialmente degradável. Seus resultados indicaram que o aumento da quantidade de amido na matriz olefínica foi responsável pela redução das propriedades mecânicas do material e formação de poros em sua estrutura.

O objetivo deste trabalho é a produção e caracterização de blendas PS/TPS, que sejam parcialmente degradáveis, usando dois plastificantes - glicerol e óleo de buriti - na tentativa de diminuir o impacto ambiental causado pelos plásticos convencionais.

\section{Experimental}

\section{Materiais}

Nessa pesquisa foram utilizados poliestireno (PS), adquirido da Aldrich Chemical Co. e fécula do amido de mandioca (Manihot esculenta Crantz) adquirida em um mercado local. A fécula foi caracterizada por análise colorimétrica segundo Chrastil ${ }^{[18]}$, possuindo $(74,70 \pm 1,76) \%$ de amilopectina.

Os plastificantes utilizados para o amido foram o glicerol obtido junto a VETEC, e óleo de buriti, gentilmente cedido pelo Prof. Dr. Sanclayton G. C. Moreira do Departamento de Física da Universidade Federal do Pará que foi mantido sob refrigeração e proteção da luz. O solvente utilizado para a preparação das blendas foi o acetato de etila de grau analítico.

\section{Métodos}

Para preparar o TPS, o amido foi colocado em estufa por 6 horas, a $120^{\circ} \mathrm{C}$, para retirar a umidade. Foram preparados dois diferentes TPS: um utilizando glicerol e outro óleo de 
buriti como plastificante. Amido, água e glicerol ou óleo de buriti na proporção 50:15:35 (m/v/v), respectivamente, foram misturados por 30 minutos, com agitação mecânica, até a obtenção de uma pasta. Esta pasta foi então aquecida em banho-maria a $95{ }^{\circ} \mathrm{C}$, com agitação constante por 1 hora, resultando em uma pasta de TPS.

As blendas foram preparadas por casting, onde PS e TPS foram misturados em diferentes proporções $(0,9: 0,1 ; 0,7: 0,3$; 0,5:0,5 e $0,3: 0,7 \mathrm{~m} / \mathrm{m}$ ) e então agitados por 3 horas a $50{ }^{\circ} \mathrm{C}$, com ocasional adição de acetato de etila quente $\left(45-50{ }^{\circ} \mathrm{C}\right)$. Os produtos obtidos foram depositados em placas de Teflon $^{\circledast}$ por pelo menos 24 horas, a temperatura ambiente e, posteriormente, submetidos a vácuo (entre 5 e 10 Torr) para total evaporação do solvente. As blendas obtidas, com espessura entre 200 e $300 \mu \mathrm{m}$, foram estocadas ao abrigo da luz para evitar a decomposição do óleo.

A estabilidade térmica dos materiais foi investigada através de um analisador termogravimétrico (TGA) Shimadzu, Modelo TGA-50. Cerca de 5,0 mg de cada amostra foram pesados em cela de platina e analizados em atmosfera de hélio $\left(50 \mathrm{~mL} \cdot \mathrm{min}^{-1}\right)$, com taxa de aquecimento de $10{ }^{\circ} \mathrm{C} \mathrm{min}^{-1}$, da temperatura ambiente até $600{ }^{\circ} \mathrm{C}$.

As análises calorimétricas foram realizadas em um calorímetro exploratório diferencial (DSC) Shimadzu, Modelo DSC-50. Cerca de 5,0 mg de cada amostra foram acondicionadas em celas de alumínio hermeticamente vedadas e resfriadas com nitrogênio líquido até $-100{ }^{\circ} \mathrm{C}$. Em seguida, as amostras foram aquecidas a $10{ }^{\circ} \mathrm{C} \mathrm{min}-1$ até $200{ }^{\circ} \mathrm{C}$, em atmosfera de hélio $\left(50 \mathrm{~mL} \cdot \mathrm{min}^{-1}\right)$. Das duas varreduras feitas para cada amostra, foi considerada a segunda para obtenção das transições termodinâmicas.

Os testes mecânicos foram realizados em um analisador termomecânico (TMA), modelo TMA-50, no modo penetração com carga de $100 \mathrm{mN}$. As curvas foram feitas em triplicata, a $10{ }^{\circ} \mathrm{C} \mathrm{min}^{-1}$, em atm de ar, da temperatura ambiente até $110^{\circ} \mathrm{C}$. A temperatura de amolecimento $\left(T_{\mathrm{a}}\right)$ foi obtida pela tangente do $1^{\circ}$ decaimento da curva.

Os experimentos de $\mathrm{RMN}{ }^{13} \mathrm{C}$, no estado sólido, com polarização cruzada $(\mathrm{CP})$ e rotação no ângulo mágico (MAS) foram feitos em um espectrômetro da Varian, modelo Mercury Plus $300 \mathrm{MHz}$, equipado com rotor de zircônio de $7 \mathrm{~mm}$ de diâmetro. Hexametilbenzeno (HMB) foi utilizado como padrão interno. Os espectros foram adquiridos com tempo de contato de $1,5 \mathrm{~ms}$, tempo de relaxação de 1 segundo, tempo de aquisição de $0,05 \mathrm{~s}$ e velocidade de $6 \mathrm{kHz}$.

Amostras de cada blenda foram aterradas, em frascos escuros perfurados ${ }^{[6]}$. Após um período de 6 meses o material foi desenterrado e limpo cuidadosamente para posterior avaliação da biodegradação por TG e CP/MAS RMN ${ }^{13} \mathrm{C}$, no estado sólido.

\section{Resultados e Discussões}

As blendas obtidas com TPS preparado com óleo de buriti apresentaram cor amarelada. Essa cor pode ser atribuída à grande concentração de carotenóides, principalmente $\beta$-caroteno, no óleo de buriti. Os carotenóides constituem uma classe de pigmentos naturais amplamente encontrados em vegetais e gorduras animais. Possuem cor intensa, variando do amarelo ao vermelho ${ }^{[16]}$.

$\mathrm{Na}$ termogravimetria (TG) a variação da massa da amostra é determinada em função da temperatura e/ou tempo, enquanto a amostra é submetida a uma programação controlada de temperatura. $\mathrm{O}$ amido degradou-se em apenas uma etapa, com temperatura de decomposição $\left(\mathrm{T}_{\mathrm{d}}\right)$ em torno de $308^{\circ} \mathrm{C}$ (Figura 1a). O glicerol também apresentou apenas uma etapa de decomposição, em torno de $213{ }^{\circ} \mathrm{C}$. A análise por TG do óleo de buriti mostrou que o óleo é mais estável termicamente que o glicerol. Sua decomposição ocorreu em duas etapas (246 e $411{ }^{\circ} \mathrm{C}$ ) (Figura 1b). A primeira etapa, mais sutil, apresentou perda de massa de $12,7 \%$ e pode ser atribuída à decomposição de ácidos graxos insaturados que compõem o óleo. Na segunda etapa de decomposição térmica

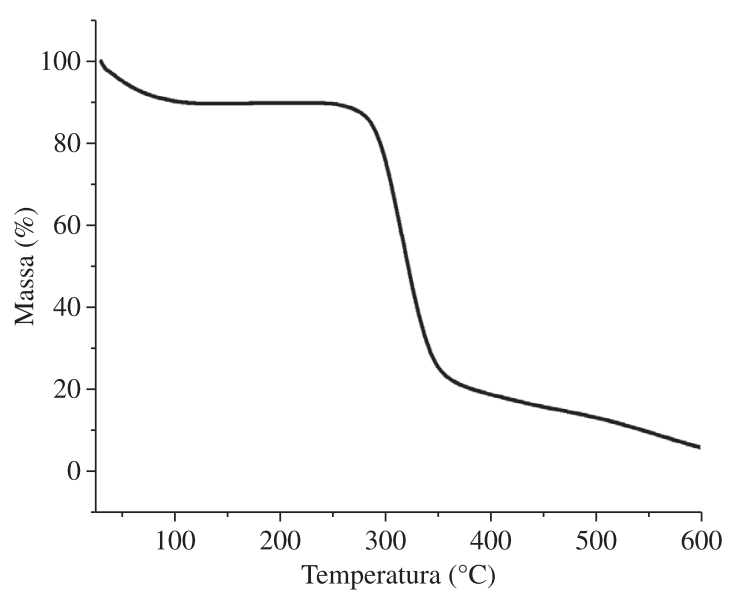

(a)

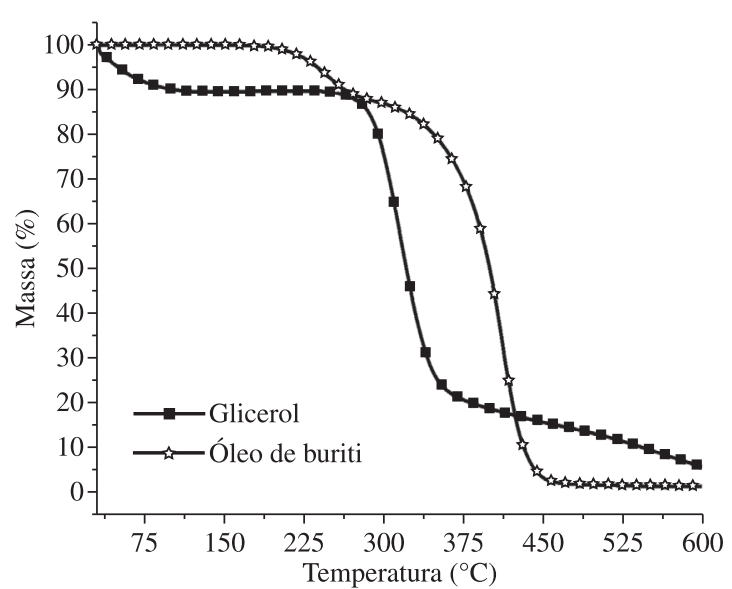

(b)

Figura 1. Curvas TG para: a) amido; e b) glicerol e óleo de buriti. 
do óleo a perda de massa foi de $85,9 \%$, e deve estar associada à degradação térmica dos ácidos graxos saturados.

A Figura 2 apresenta as curvas TG obtidas para o PS, TPS e as blendas PS/TPS utilizando glicerol (Figura 2a) e óleo de buriti (Figura 2b) como plastificante.

Foi observado que a adição de TPS, independentemente do plastificante usado, conferiu ao PS maior facilidade de degradação térmica. As blendas obtidas com glicerol degradaram em mais etapas e em temperaturas menores comparadas àquelas produzidas com óleo de buriti. Isto sugere que o óleo de buriti, quando usado como plastificante do amido, produz blendas termicamente mais estáveis do que o glicerol ${ }^{[15]}$.

Para todas as blendas estudadas a última etapa de degradação refere-se à despolimerização do PS $\left(429^{\circ} \mathrm{C}\right)$ e a penúltima à decomposição do TPS. A porcentagem de perda de massa tem relação direta com a quantidade de amido nas blendas. As demais etapas das curvas TG podem estar relacionadas com frações dos plastificantes que não foram incorporados à matriz, principalmente, para nas blendas com maior percentual de TPS.

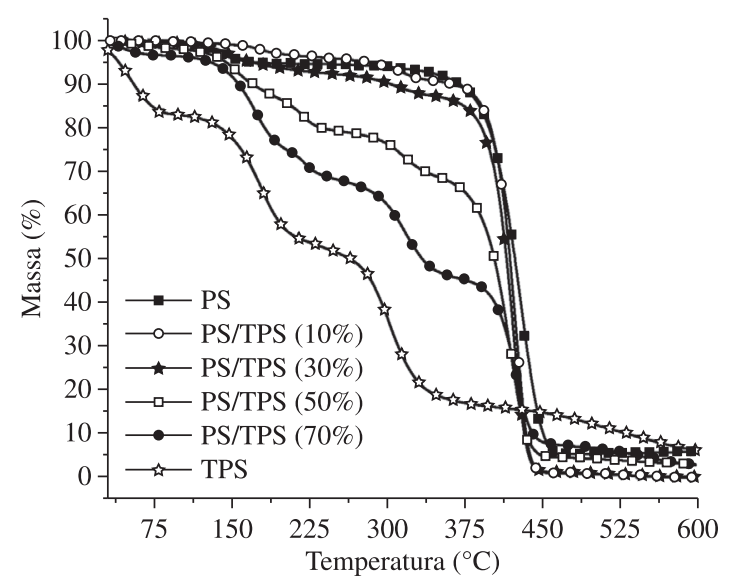

(a)

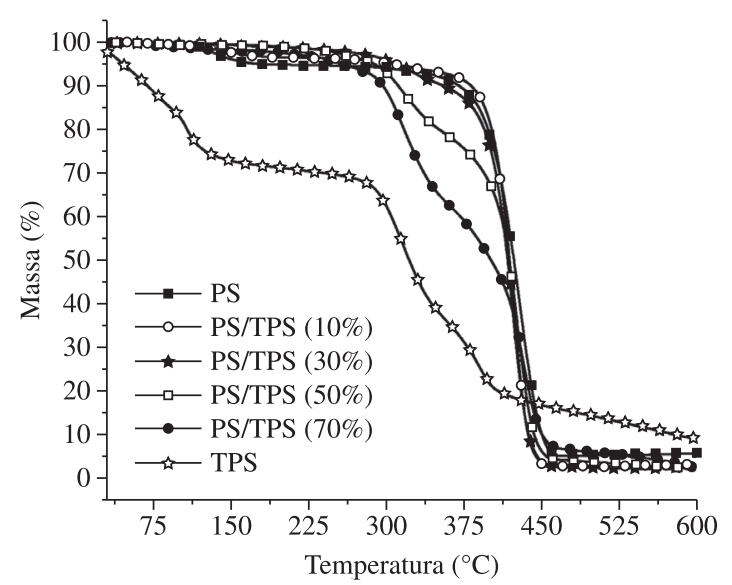

(b)

Figura 2. Curvas TG para PS, TPS e as blendas PS/TPS: a) com glicerol; e b) com óleo de buriti.
Em um termograma de DSC, picos exotérmicos e endotérmicos caracterizam transições ou reações que tenham ocorrido durante a análise, como transição vítrea, gelatinização, fusão, oxidação e decomposição, entre outras.

A curva DSC obtida para o amido (Figura 3) apresentou um pico endotérmico bastante largo, de 15 a $145{ }^{\circ} \mathrm{C}$

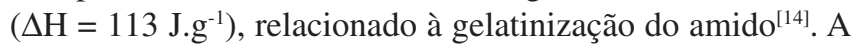
gelatinização é definida como uma transição ordem-desordem que envolve a ruptura da organização molecular dentro dos grânulos de amido, sob aquecimento e na presença de plastificantes. Por comparação com os polímeros sintéticos pôde ser proposto que a dependência da temperatura nessa perda de cristalinidade varia com o polimorfismo dos cristais, seu grau de perfeição, o comprimento de cadeia envolvido na unidade cristalina e a quantidade de plastificante utilizado ${ }^{[2]}$.

Nas blendas com amido o plastificante atua rompendo as ligações de hidrogênio amido-amido entre hélices de amilopectina e formando ligações de hidrogênio amidoplastificante simultaneamente. $\mathrm{O}$ ingresso do solvente nos grânulos é um importante passo antes que a clivagem das ligações de hidrogênio amido-amido aconteça ${ }^{[19]}$.

Na curva DSC obtida para o glicerol foi observada uma redução na capacidade calorífica próxima a $-80{ }^{\circ} \mathrm{C}$ que pode ser atribuída à transição vítrea do plastificante ${ }^{[15,20]}$. A curva de DSC para o óleo de buriti mostrou um pico endotérmico bastante intenso, próximo a $-7^{\circ} \mathrm{C}$, que pode estar associado a uma transição de fase sólido-sólido, do tipo ordem-desordem $(\gamma \rightarrow \alpha)$, referente ao ácido oléico, que ocorre em $-2,2{ }^{\circ} \mathrm{C}^{[15,21]}$. Esses picos endotérmicos intensos só aparecem nas blendas de 50 e $70 \%$, ou seja, com maiores teores de TPS

Um dado importante retirado das curvas de DSC é a temperatura de transição vítrea $\left(\mathrm{T}_{\mathrm{g}}\right)$. A $\mathrm{T}_{\mathrm{g}}$ é um valor referente a uma faixa de temperatura que, durante $o$ aquecimento de um material polimérico, permite que as cadeias da fase amorfa adquiram mobilidade. As Figuras $4 \mathrm{a}, \mathrm{b}$ mostram as curvas de DSC obtidas para o PS e para as blendas PS/TPS com glicerol e óleo de buriti, respectivamente. Na Tabela 1 estão listados os valores das $\mathrm{T}_{\mathrm{g}}$, obtidos a partir destas curvas.

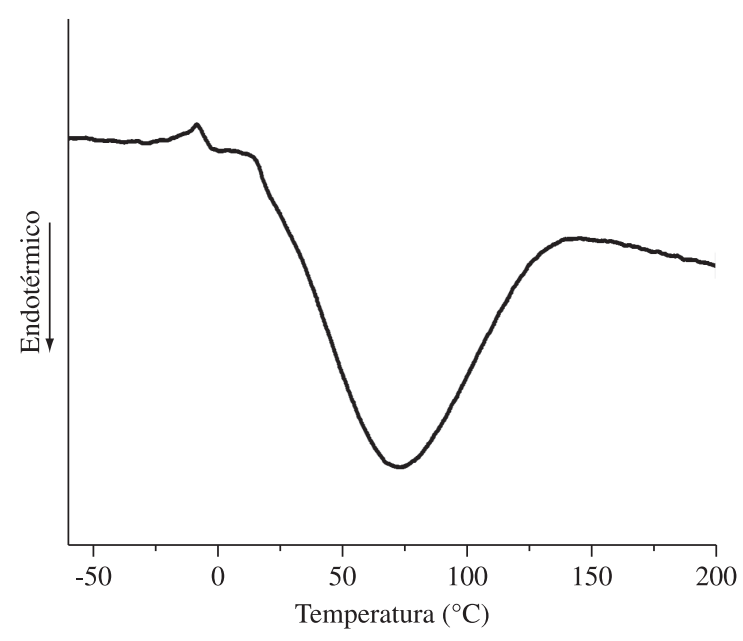

Figura 3. Curva DSC para o amido puro. 


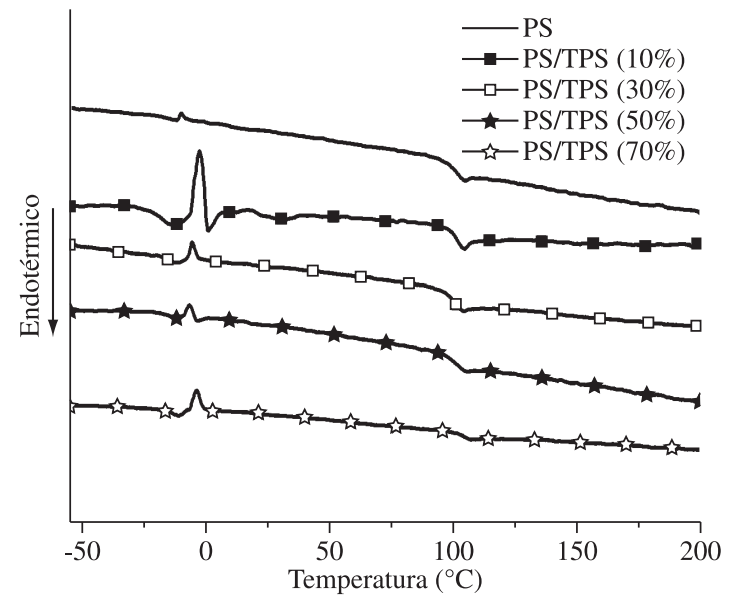

(a)

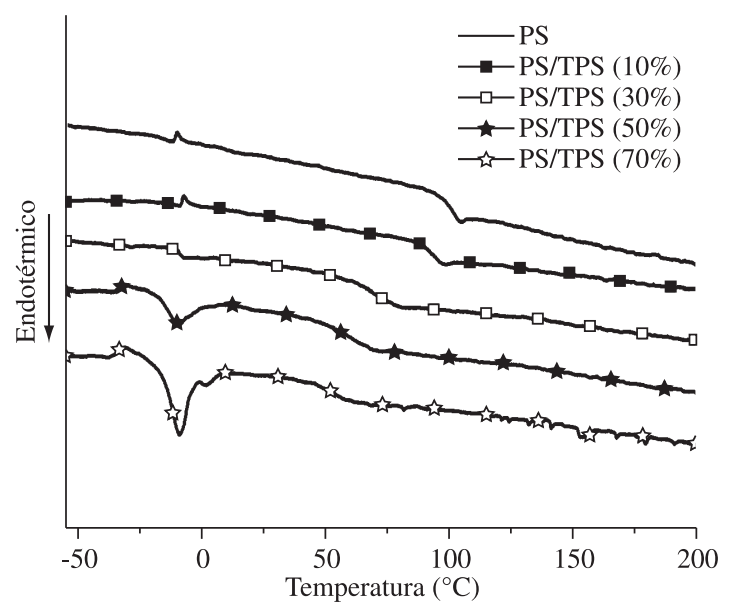

(b)

Figura 4. Curvas DSC para o PS e PS/TPS com a) glicerol; e b) óleo de buriti.

Tabela 1. Valores da $T_{p}$ para o PS e para as blendas PS/TPS.

\begin{tabular}{cccc}
\hline $\begin{array}{c}\text { TPS com } \\
\text { glicerol (\%) }\end{array}$ & $\mathbf{T}_{\mathrm{g}}\left({ }^{\circ} \mathbf{C}\right)$ & $\begin{array}{c}\text { TPS com óleo } \\
\text { de buriti }(\%)\end{array}$ & $\mathbf{T}_{\mathrm{g}}\left({ }^{\circ} \mathbf{C}\right)$ \\
\hline 0 & 102 & 0 & 102 \\
10 & 102 & 10 & 95 \\
30 & 100 & 30 & 75 \\
50 & 101 & 50 & 64 \\
70 & 105 & 70 & 54 \\
\hline
\end{tabular}

Pelos dados de DSC percebe-se que todas as blendas PS/TPS possuem características intermediárias entre o PS puro e o TPS. Nas curvas de DSC das blendas com glicerol observou-se que a $\mathrm{T}_{\mathrm{g}}$ permaneceu praticamente constante apesar do incremento de TPS. Este fenômeno é conhecido como antiplastificação e, para materiais à base de amido, ocorre quando são usados como plastificante glicerol e água em pequena quantidade. Quando a água é utilizada em quantidade suficiente o glicerol volta a se comportar como um plastificante eficiente ${ }^{[22]}$. As causas desse efeito em materiais a base de amido ainda não foram claramente elucidadas, mas a mobilidade molecular tem um papel preponderante nos mecanismos envolvidos.

Nas curvas de DSC das blendas com óleo de buriti percebeu-se que quando a concentração de TPS na blenda aumentou a $\mathrm{T}_{\mathrm{g}}$ diminuiu em relação à do PS. O óleo de buriti comportou-se como um plastificante intraestrutural, caracterizado por uma diminuição contínua na $T_{g}$ com o aumento da quantidade de plastificante $\mathrm{e}^{[11,22]}$.

A técnica de TMA avalia as mudanças dimensionais de materiais em função da temperatura, tempo ou força. Neste trabalho foi utilizada a sonda de penetração, que permite a identificação do ponto de amolecimento de um material, ou seja, fornece a temperatura de amolecimento $\left(\mathrm{T}_{\mathrm{a}}\right)$, caracterizada pelo início da penetração da ponta de quartzo da sonda na amostra em função da temperatura.

A Tabela 2 apresenta os valores médios da $\mathrm{T}_{\mathrm{a}}$ obtidos para as amostras de PS e para as blendas PS/TPS.

Os dados mostram que a $T_{\text {p }}$ permaneceu aproximadamente constante para todas as blendas com glicerol e diminui com o aumento da concentração de óleo para as blendas com óleo de buriti. Esses dados estão de acordo com os valores de $T_{g}$ obtidos por DSC. Essas observações sugerem que as blendas com glicerol apresentam propriedades termomecânicas semelhantes ao PS puro, no que se refere resistência à penetração. Sabendo que a incorporação de um plastificante torna a rede polimérica menos densa e, consequentemente, mais permeável, esses dados indicam que a ação plastificante do óleo de buriti para o amido, nas condições estudadas, foi mais eficiente que a do glicerol. Vale salientar que, ao contrário das blendas com glicerol, todas as blendas com óleo de buriti apresentaram valor de $\mathrm{T}_{\mathrm{a}}$ menor do que o valor da T do PS.

A espectroscopia de $\mathrm{RMN}{ }^{13} \mathrm{C}$, no estado sólido, é uma ferramenta muito utilizada no estudo e caracterização de polímeros. O espectro de CP/MAS RMN ${ }^{13} \mathrm{C}$ para o amido da mandioca (Figura 5a) apresenta um dupleto em 97 e 98 ppm e um "ombro" em 99 ppm, que pode ser originário dos domínios amorfos de C-1. Um sinal em 58 ppm é atribuído ao carbono 6 da molécula de glicose. $\mathrm{O}$ sinal de maior intensidade em todo o espectro, 68 ppm, é associado aos carbonos C-2, C-3 e C-5 $5^{[22]}$.

$\mathrm{O}$ pico em 68 ppm é relacionado aos grupos $\mathrm{CH}-\mathrm{OH}$, enquanto os picos próximos a 100 ppm são relacionados ao

Tabela 2. Valores da $T_{a}$ para o PS e para as blendas PS/TPS.

\begin{tabular}{|c|c|}
\hline Amostras & $\mathbf{T}_{\mathrm{a}}\left({ }^{\circ} \mathbf{C}\right)$ \\
\hline PS & 84 \\
\hline PS/TPS ${ }_{\mathrm{G}}(10 \%)$ & 84 \\
\hline PS/TPS ${ }_{\mathrm{G}}(30 \%)$ & 80 \\
\hline $\mathrm{PS} / \mathrm{TPS}_{\mathrm{G}}(50 \%)$ & 81 \\
\hline $\mathrm{PS} / \mathrm{TPS}_{\mathrm{G}}(70 \%)$ & 83 \\
\hline $\mathrm{PS} / \mathrm{TPS}_{\mathrm{OB}}(10 \%)$ & 83 \\
\hline $\mathrm{PS} / \mathrm{TPS}_{\mathrm{OB}}(30 \%)$ & 77 \\
\hline $\mathrm{PS} / \mathrm{TPS}_{\mathrm{Oв}}(50 \%)$ & 69 \\
\hline $\mathrm{PS} / \mathrm{TPS}_{\mathrm{Oв}}(70 \%)$ & 62 \\
\hline
\end{tabular}




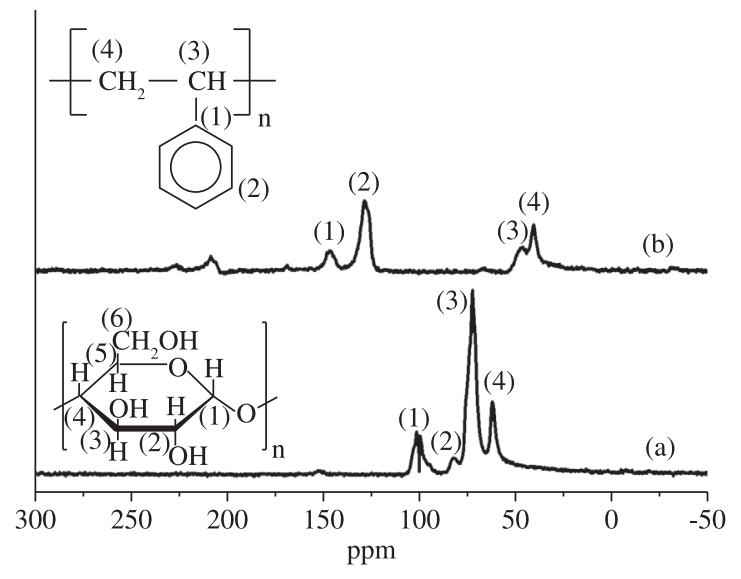

Figura 5. Espectros de CP/MAS RMN ${ }^{13} \mathrm{C}$, no estado sólido, do a) amido; e do b) PS.

carbono anomérico dos grupos $\mathrm{CH}-(\mathrm{OR})_{2}$. O carbono $\mathrm{C}-1$ está ligado a dois átomos de oxigênio e com isso apresenta um deslocamento químico maior que C-4 que está ligado a somente um oxigênio.

No espectro do PS (Figura 5b) há deslocamentos em 147 e 128 ppm devidos aos carbonos aromáticos nãoprotonados e protonados, respectivamente. As ressonâncias dos carbonos metínico e metilênico estão localizadas em 47 e $41 \mathrm{ppm}$, respectivamente.

Foi observado que, quanto maior o teor de TPS na blenda, maior a intensidade dos deslocamentos referentes às ligações C-O, localizados entre 58 e 78 ppm, característicos do amido. Infere-se que não há fortes ligações químicas entre os componentes das blendas, pois não há deslocamento de picos e nem aparecimento de novos picos ${ }^{[23]}$.

A degradação de um polímero é um processo irreversível, ocasionado por vários fatores responsáveis pela perda de suas propriedades. Nesse processo, em geral, ocorre cisão da cadeia polimérica e alterações estruturais causadas por outros mecanismos. Estudos sobre blendas de polímeros petroquímicos com amido indicam que o amido pode acelerar o processo de degradação do polímero sintético. O consumo do amido circundante pelos microorganismos faz com que aja deterioração das propriedades mecânicas, facilitando a quebra do material por outros mecanismos de degradação e deixando a matriz polimérica suscetível ao ataque de microorganismos ${ }^{[5,6]}$.

A partir das curvas TG para as blendas PS/TPS com glicerol (Figura 6a) pode-se verificar que todas as amostras apresentaram um número menor de etapas de degradação térmica após o período de aterro. Os valores de $\mathrm{T}_{\mathrm{d}}$ associados à decomposição térmica do PS permaneceram praticamente inalterados, antes e após o período de aterro, indicando que a estrutura do PS foi mantida após os 6 meses no solo.

As curvas TG das blendas PS/TPS com óleo de buriti (Figura 6b) apresentaram, após os 6 meses de aterro, apenas uma etapa de degradação térmica, correspondente ao PS, com valor de $\mathrm{T}_{\mathrm{d}}$ próximo ao da amostra original, mas com

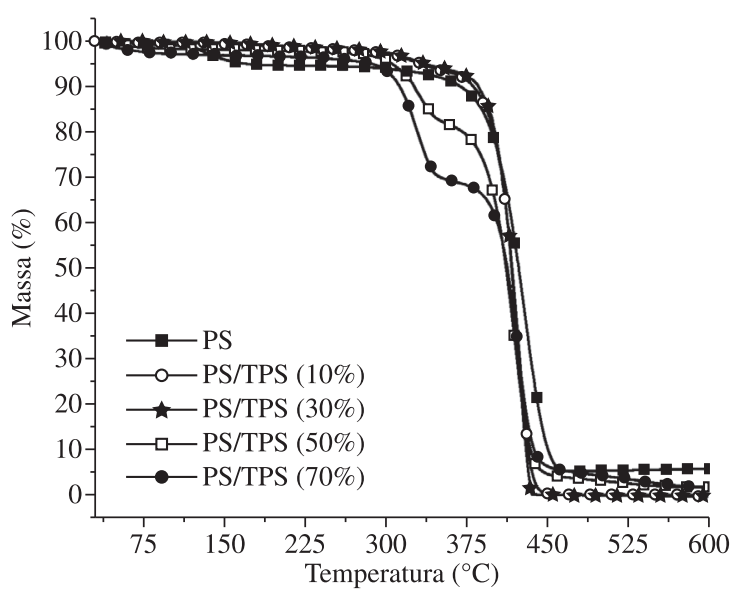

(a)

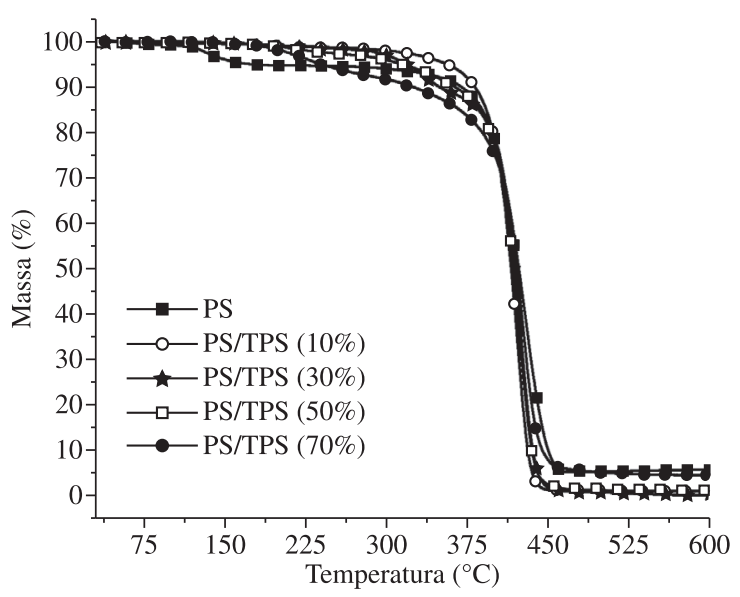

(b)

Figura 6. Curvas TG para PS e as blendas PS/TPS: a) com glicerol; e b) com óleo de buriti, após 6 meses de aterro.

um significativo aumento na perda de massa ( 30\%). Isto pode ser considerado um indicativo de degradação através de uma provável redução no comprimento das cadeias moleculares ${ }^{[8]}$.

Após o aterro, todas as blendas com glicerol apresentam espectros de RMN semelhantes. Ou seja, os espectros mostraram picos característicos do amido e do PS, antes e após o período no solo. Esses resultados estão em concordância com os dados obtidos por TG que mostraram que as blendas com glicerol apresentam etapas de degradação referentes ao amido, mesmo após o tempo de aterro ${ }^{[24]}$.

Os espectros de CP/MAS RMN ${ }^{13} \mathrm{C}$ para as blendas PS/TPS glicerol e com óleo de buriti (5:5), antes e após o aterro estão mostrado na Figura 7, como exemplo.

Ao contrário das blendas com glicerol, todas as blendas PS/TPS com óleo de buriti apresentaram apenas os picos referentes ao PS após o tempo de aterro, com desaparecimento dos picos entre 55 e 110 ppm. Isto confirma a informação obtida através das curvas TG, de que praticamente todo o amido das blendas com óleo de buriti foi consumido após o período de degradação no solo ${ }^{[24]}$. 


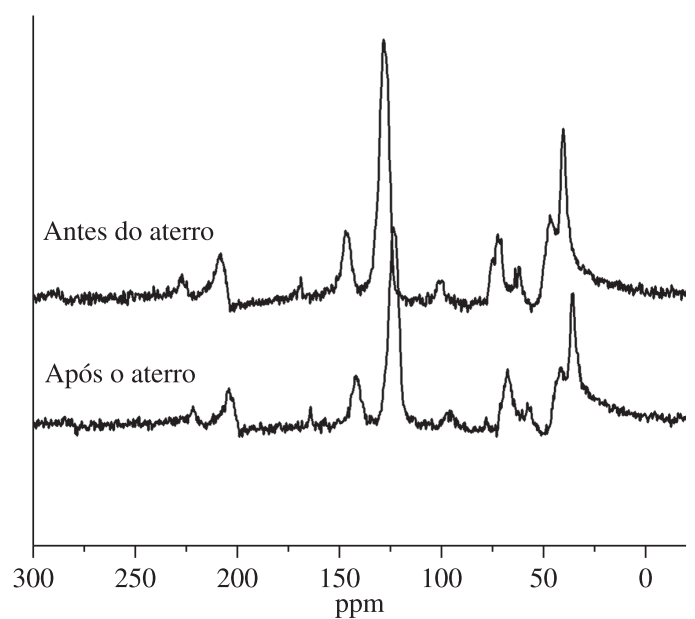

(a)

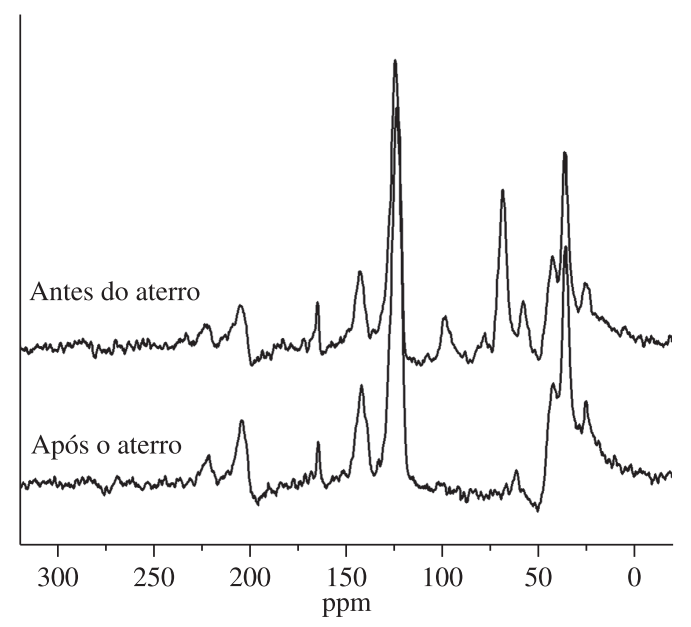

(b)

Figura 7. Espectros de CP/MAS RMN ${ }^{13} \mathrm{C}$, no estado sólido, das blendas PS/TPS a) com glicerol; e b) com óleo de buriti (0,5:0,5), antes e após o aterro.

Cadeias longas de hidrocarbonetos são muito resistentes à biodegradação porque não existem enzimas capazes de promover a quebra dessas ligações C-C. Os mecanismos envolvidos na biodegradação do PS são complexos, devido a vários processos oxidativos que podem ser causados pelo oxigênio do ar, pelos microorganismos, ou por uma combinação dos dois.

\section{Conclusões}

As blendas PS/TPS com glicerol degradam em um número maior de etapas e em temperaturas inferiores comparadas àquelas produzidas com óleo de buriti, sugerindo que o óleo de buriti, quando usado como plastificante do amido, produz blendas termicamente mais estáveis. Em concordância com os dados de DSC, os resultados de TMA indicaram que a ação plastificante do óleo de buriti para o amido, nas condições estudadas, foi mais eficiente que a do glicerol. Nas blendas com glicerol, tanto a $\mathrm{T}_{\mathrm{g}}$ como a $\mathrm{T}_{\mathrm{a}}$ permaneceram praticamente constantes, apesar do incremento de TPS.
Entretanto, as blendas com óleo de buriti mostraram que, quando a concentração de TPS aumenta, a $\mathrm{T}_{\mathrm{g}}$ e a $\mathrm{T}_{\mathrm{a}}$ diminuem em relação à $\mathrm{T}_{\mathrm{g}}$ e a $\mathrm{T}_{\mathrm{a}}$ do $\mathrm{PS}$ puro.

Os resultados das blendas PS/TPS aterradas mostraram que houve consumo do amido apenas para as blendas com óleo de buriti. Os dados indicam que essas blendas com o óleo têm maior facilidade de degradação em aterro, nas condições estudadas. Portanto, os materiais produzidos com óleo de buriti apresentam, além de um melhor efeito plastificante, uma maior suscetibilidade à degradação no solo do que as blendas produzidas com glicerol. A blenda PS/TPS $(50 \%)$ é a que apresenta melhor relação resistência/ degradabilidade. Isso sugere que as blendas com óleo de buriti são mais promissoras no que se refere à futura produção de um material parcialmente degradável.

\section{Agradecimentos}

Os autores agradecem ao IQ-UnB e ao CNPq pelo suporte financeiro.

\section{Referências Bibliográficas}

1. Lorcks, J. - Polym. Degrad. Stab., 59, p.245 (1998).

2. Parker, R. \& Ring, S.G. - J. Cereal Sci., 34, p.1 (2001).

3. Tester, R. F.; Karkalas, J. \& Qi, X. - J. Cereal Sci., 39, p.151 (2004).

4. Corradini, E.; Lotti, C.; Medeiros, E. S.; Carvalho, A. J. F.; Curvelo, A. A .S. \& Mattoso, L. H. C. - Polímeros Cienc Tecnol., 15, p.268 (2005).

5. Zuchowska, D.; Steller, R. \& Meissner, W. - Polym. Degrad. Stabil., 60, p.471 (1998).

6. Kiatkamjornwong, S.; Sonsuk, M.; Wittayapichet, S.; Prasassarakich, P. \& Vejjanukroh, P. C. - Polym. Degrad. Stabil., 66, p.323 (1999).

7. Thakore, I. M.; Desai, S.; Sarawade, B. D. \& Devi, S. Eur. Polym. J., 37, p.151 (2001).

8. El-Rehim, H. A. A.; Hegazy, E. S. A.; Ali, A. M. \& Rabie, A. M. - J. Photochem. Photobiol. A, 163, p.547 (2004).

9. Ramis, X.; Cadenato, A.; Salla, J. M.; Morancho, J. M.; Valles, A.; Contat, L. \& Ribes, A. - Polym. Degrad. Stabil., 86, p.483 (2004).

10. Nakamura, E. M.; Cordi, L.; Almeida, G. S. G.; Duran, N. \& Mei, L. H. I. - J. Mater. Process. Technol., 162, p.236 (2005).

11. Miles, D. C. \& Briston, J. H. - “Tecnologia de Polímeros”, Editora Polígono S.A, São Paulo (1975).

12. Fang, P. A.; Fowler, P. A.; Tomkinson, J. \& Hill, C. A. S. - Carbohydr. Polym., 50, p.429 (2002).

13. Durães, J. A.; Drummond, A. L.; Pimentel, T. A. P. F.; Murta, M. M.; Bicalho, F. S.; Moreira, S. G. C. \& Sales, M. J. A. - Europ. Polym. J., 42, p.3324 (2006). 
14. Pimentel, T. A. P. F.; Durães, J. A.; Drummond, A. L.; Schlemmer, D.; Falcão, R. \& Sales, M. J. A. - J. Mater. Sci., 42, p.7530 (2007).

15. Schlemmer, D.; Oliveira, E. R. \& Sales, M. J. A. - J. Therm. Anal. Calorim., 87, p.635 (2007).

16. Albuquerque, M. L. S.; Guedes, I.; Alcântara Jr., P.; Moreira, S. G. C.; Barbosa Neto, N. M.; Correa, D. S. \& Zílio, S. C. - J. Brazil. Chem. Soc., 16, p.1113 (2005).

17. Mano, E. B. \& Mendes, L. C. - "Introdução a Polímeros", Edgard Blüncher Ltda, São Paulo (2001).

18. Chrastil, J. - Carbohydr. Res., 159, p.154 (1987).

19. Tan, I.; Wee, C. C.; Sopade, P. A. \& Halley, P. J. Carbohydr. Polym., 58, p.191 (2004).
20. Averous, L; Moro, L.; Dole, P. \& Fringant C. - Polymer, 41, p.4157 (2000).

21. Tandon, G.; Forster, G.; Neubert, R. \& Wartewig, S. - J. Molec. Struct., 524, p.201 (2000).

22. Chang, Y. P.; Karim, A. A. \& Seow, C. C. - Food Hydrocolloids, 20, p.1 (2006).

23. Schlemmer, D.; Sales, M. J. A \& Resck, I. S. - Carbohydr. Polym., 75, p.58 (2008).

24. Atichokudomchau, N.; Varavinit, S. \& Chinachoti, P. Carbohydr. Polym., 58, p.383 (2004).

Enviado: 20/03/09

Reenviado: 11/10/09

Aceito: 14/10/09

DOI: $10.1590 / \mathrm{S} 0104-14282010005000002$ 